\title{
Formulation and Evaluation of Fixed-Dose Combination Immediate Release Tablets of Ibuprofen and Famotidine through Quality by Design Approach
}

\author{
Md. Mahbubul Alam, Md. Shahidul Islam, K. M. Yasif Kayes Sikdar \\ and A. S. M. Monjur-Al-Hossain \\ Department of Pharmaceutical Technology, Faculty of Pharmacy, University of Dhaka, \\ Dhaka-1000, Bangladesh.
}

(Received: June 10, 2021; Accepted: July 3, 2021; Published (Web): July 15, 2021)

\begin{abstract}
Nonsteroidal anti-inflammatory drugs (NSAIDs) are frequently prescribed by the physicians for the management of pain due to their anti-inflammatory and analgesic properties. Long term use of NSAIDs causes gastrointestinal (GI) toxicity and the common GI disorders are indigestion, ulcers or bleeding. Therefore, the production of local oral tablets containing NSAIDs and gastro-protectant is inevitable. In this experiment, combination of ibuprofen $600 \mathrm{mg}$ and famotidine $20 \mathrm{mg}$ tablets were prepared by direct compression technique, which is unique in Bangladesh. To pursue the study Design of Experiments (DoE) approach was implemented to create fifteen trial formulations where Polyvinylpyrrolidone (PVPK30) $1 \%-3 \%$, Microcrystalline Cellulose (Avicel PH-102) 1\%-7\% and Starch-1500 1\%-13\% were considered as independent variables and the responses were depicted in friability and disintegration time which were found $0.21-0.45 \%$ and $1.8-20.5$ minutes respectively. Out of fifteen formulation trials (F-1 to F-15), seven formulations (F-3, F-6, F-8, F-9, F-10, F-13 and F-14) had met the acceptable criteria and one formulation (F-9) with independent variables PVP-K30 2.00\%, Avicel PH-102 $4.75 \%$ and Starch-1500 6.5\% was selected because of its better disintegration, dissolution and friability profile. Data obtained from in-vitro dissolution tests were fitted to different kinetic models such as zero order, first order, Higuchi, Hixson-Crowell and Korsmeyer-Peppas models. Also, a compatibility study was conducted using Fourier Transform Infrared Spectroscopy (FTIR), Thermogravimetric Analysis (TGA) and X-Ray Diffraction (XRD). Furthermore, Scanning Electron Microscopy (SEM) was performed to analyze surface morphology. Finally, the selected formulation was compared to FDA regulated QC parameters and proved its superiority over conventional market products.
\end{abstract}

Key words: Nonsteroidal anti-inflammatory drugs (NSAIDs), Gastro-protectant, Ibuprofen, Famotidine, Design of Experiments (DoE).

\section{Introduction}

Worldwide most commonly prescribed and widely used medicines for musculoskeletal disorders and pain management are NSAIDs (Al-Saeed, 2011; Lanza et al., 2009). Bangladesh is no exception from this, as about $87 \%$ of its populace take NSAIDs as over-the-counter (OTC) or without prescription or consultation with health care professionals (Karim and Banoo, 2012). Reckless intake of these medicines is associated with several upper GI tract complications, like abdominal discomfort, dyspepsia, erosions, ulcers, hemorrhage and perforation (Roth, 2012). Proton pump inhibitors (PPIs), or histamine receptor $2\left(\mathrm{H}_{2}\right)$ antagonist are currently being used to tackle these NSAIDs induced GI injuries. However, due to the complexity of multi-agent regimen dosage schedules patient adherence to such gastro-protective co-therapy can be very poor (Bello, 2012). Therefore, the present research work has been designed to develop and evaluate a fixed-dose formulation

Corresponding author: A. S. M. Monjur-Al-Hossain; Email: monjur.shiplu@ du.ac.bd

DOI: https://doi.org/10.3329/bpj.v24i2.54712 
combining an NSAID with a gastro-protective agent to simplify treatment regimens and improving patient adherence to co-therapy.

In this present work, ibuprofen $600 \mathrm{mg}$ and famotidine $20 \mathrm{mg}$ were selected. By considering the issues like tolerability in children under 12 years of old or absence of any heart or blood pressure related side effects and in terms of incompatibility or reactivity with other drugs, ibuprofen was found auspicious over other conventionally prescribed or used NSAIDs like naproxen, ketoprofen or diclofenac (Slowiczek, 2018). On the other hand, among others generics of gastro-protective agents, PPIs are reproached with lowering the abundance of microbial diversity in upper GI tract commensals (Jackson et al., 2016). However, famotidine was found superior over ranitidine and cimetidine which are censured with the presence of human carcinogens like $\mathrm{N}$ nitrosodiethylamine (NMDA) and anti-androgenic effects respectively (Vakil, 2020). USFDA and UKNHS also recommend using combination product for the management of rheumatoid arthritis and osteoarthritis and to minimize the GI related disorders (Deeks, 2013).

The present work focuses on DoE, which is a statistical approach that correlates the most important input factors with their optimized output responses (Bhutani et al., 2004). Tablets prepared by direct compression method may need acceptable friability and sufficient disintegration property. To achieve these properties pose a challenge for the formulation scientists. Therefore, three vital formulation carriers such as PVP-K30, Avicel PH-102 and Starch-1500 of varying concentrations were considered as input factors and their output responses were illustrated into friability and disintegration time and the connection of interactions between those input factors on the formulations were manifested.

\section{Materials and Methods \\ Materials}

Ibuprofen and famotidine drug substances were provided as a humble open-handed contribution by Incepta Pharmaceuticals Limited, Bangladesh and
Square Pharmaceuticals Limited, Bangladesh respectively. Moreover, Starch-1500 and Avicel PH102 were purchased from Colorcon Asia Pvt. Ltd, India. Furthermore, Colloidal Silicon Dioxide, PVPK30 and Magnesium Stearate respectively were collected from the Pharmaceutics research lab, University of Dhaka, Bangladesh. Deionized water was supplied by a water purifier system (Millipore Milli-Q from Bedford, MA, USA).

\section{Methods}

Formulation design: In this study DoE approach was implemented, which involves controlled variable and as the outcome of the controlled variable response is obtained (Bhutani et al., 2004). PVP-K30, Avicel PH-102 and Starch-1500 were considered as independent variables in this study while the responses were friability in percentage and disintegration time (in minutes). Considering these variables, 15 formulations were developed by the Design Expert ${ }^{\circledR}$ software (version 12) where the percentage of highest and lowest limits of the controlled variables were $1 \%-3 \%, 1 \%-7 \%$ and $1 \%$ $13 \%$ for PVP-K30, Avicel PH-102 and Starch-1500 respectively. Software generated amounts of three variables are given in table 1 and the overall formulation of 15 different batches are shown in table 2.

Formulation of immediate-release tablets: Direct compression method was applied in this study to prepare immediate-release tablets. Initially, active pharmaceutical ingredient (API) and excipients were passed through mesh screen number 30 and were weighed accurately for 18 tablets per formulation. All excipients except the lubricant were mixed through proper trituration for 30 minutes in mortar and pestle along with the drugs. Previously sieved and accurately weighed amount of magnesium stearate (lubricant) was then added and mixed further for another 10 minutes. After mixing, physical property characterization tests were done to evaluate the powder mixture followed by compression in ZP-17 E rotary tablet press machine, Shanghai Pharmaceutical Machinery Co. Ltd., China. 
Table 1. Software generated amount (in percentage) of three variables in different formulations.

\begin{tabular}{cccc}
\hline Formulation number & PVP-K30 & Avicel PH-102 & Starch-1500 \\
\hline F-1 & 1 & 1 & 1 \\
F-2 & 3 & 1 & 10 \\
F-3 & 2.75 & 4 & 5.5 \\
F-4 & 1.5 & 4 & 5.5 \\
F-5 & 2 & 6.5 & 5.5 \\
F-6 & 1 & 1 & 10 \\
F-7 & 3 & 7 & 10 \\
F-8 & 2 & 4 & 9.5 \\
F-9 & 2 & 4.75 & 6.5 \\
F-10 & 1 & 7 & 10 \\
F-11 & 2 & 4 & 6.5 \\
F-12 & 2 & 1.5 & 5.5 \\
F-13 & 3 & 7 & 1 \\
F-14 & 1 & 7 & 1 \\
F-15 & 3 & 1 & 1 \\
\hline
\end{tabular}

Table 2. Composition of Ibuprofen (IBU) and Famotidine (FAM) immediate-release tablets (all measurements are in mg).

\begin{tabular}{cccccccccc}
\hline $\begin{array}{c}\text { Formulation } \\
\text { number }\end{array}$ & IBU & FAM & PVP-K30 & $\begin{array}{c}\text { Avicel } \\
\text { PH-102 }\end{array}$ & Starch 1500 & $\begin{array}{c}\text { Lactose } \\
\text { Monohydrate }\end{array}$ & Mg-stearate & Aerosil & Total Wt. \\
\hline F-1 & 600 & 20 & 8 & 8 & 8 & 150 & 4 & 2 & 800 \\
F-2 & 600 & 20 & 24 & 8 & 80 & 62 & 4 & 2 & 800 \\
F-3 & 600 & 20 & 22 & 32 & 44 & 76 & 4 & 2 & 800 \\
F-4 & 600 & 20 & 12 & 32 & 44 & 86 & 4 & 2 & 800 \\
F-5 & 600 & 20 & 16 & 52 & 44 & 62 & 4 & 2 & 800 \\
F-6 & 600 & 20 & 8 & 8 & 80 & 78 & 4 & 2 & 800 \\
F-7 & 600 & 20 & 24 & 56 & 80 & 14 & 4 & 2 & 800 \\
F-8 & 600 & 20 & 16 & 32 & 76 & 50 & 4 & 2 & 800 \\
F-9 & 600 & 20 & 16 & 38 & 52 & 68 & 4 & 2 & 800 \\
F-10 & 600 & 20 & 8 & 56 & 80 & 30 & 4 & 2 & 800 \\
F-11 & 600 & 20 & 16 & 32 & 52 & 74 & 4 & 2 & 800 \\
F-12 & 600 & 20 & 16 & 12 & 44 & 102 & 4 & 2 & 800 \\
F-13 & 600 & 20 & 24 & 56 & 8 & 86 & 4 & 2 & 800 \\
F-14 & 600 & 20 & 8 & 56 & 8 & 102 & 4 & 2 & 800 \\
F-15 & 600 & 20 & 24 & 8 & 8 & 134 & 4 & 2 & 800 \\
\hline
\end{tabular}

Pre-compression evaluation of powder blends: After mixing the ingredients and before compression several tests were done according to established reference procedure to evaluate the powder blends named loose bulk density, tapped bulk density
(World Health Organization, 2012), Carr's index, Hausner's ratio and angle of repose (Pharmacopoeia, U.S., 2004).

Characterization of physical properties of formulated tablets: Weight variation of the tablets 
were evaluated through an electronic balance of Electrolab India Pvt. Ltd. 20 tablets of each formulation were considered for this test according to official method. Also, hardness, thickness and friability of the formulated tablets (six tablets of each formulation) were performed according to compendial method using automatic tablet hardness tester of Electrolab India Pvt. Ltd., slide calipers of Yuyao Haiju Lab Equip. Co. Ltd, China and friabilator of Electrolab India Pvt. Ltd. respectively (Chandrasekaran, 2011).

Preparation of phosphate buffer: $50 \mathrm{mM}$ of potassium phosphate buffer of $\mathrm{pH} 7.2$ were prepared by following USP method (AAT Bioquest, Inc., 2021). $5.37 \mathrm{~g}$ potassium hydrogen phosphate $\left(\mathrm{K}_{2} \mathrm{HPO}_{4}\right)$ and $2.61 \mathrm{~g}$ potassium di-hydrogen phosphate $\left(\mathrm{KH}_{2} \mathrm{PO}_{4}\right)$ were taken in a $1000 \mathrm{ml}$ volumetric flask and filled up to $800 \mathrm{ml}$ with deionized water followed by sonication for 10 minutes in a sonicator of Human Lab Instrument Co., South Korea. Then rest of the water was added to the final mark $(1000 \mathrm{ml})$ and again sonicated for 5 minutes. To maintain the $\mathrm{pH}$ potassium hydroxide solution was considered and it was refrigerated for further use but before conducting any analysis $\mathrm{pH}$ of the solution was measured accordingly with the help of CyberScan $500 \mathrm{pH}$ Meter, Eutech Instruments Pvt. Ltd., Singapore. This phosphate buffer solution was considered as dissolution medium and diluting solution or mobile phase throughout the experiment.

Preparation of standard curve for ibuprofen and famotidine: $10 \mathrm{mg}$ of ibuprofen and famotidine were taken in two separate $100 \mathrm{ml}$ volumetric flasks and made up the volume with the aforementioned phosphate buffer followed by proper sonication for 5 minutes and named as the stock solution having a final concentration of $100 \mu \mathrm{g} / \mathrm{ml}$ for ibuprofen and famotidine respectively. From the above solution through serial dilution with the phosphate buffer, five different concentration of sample solutions (1, 2, 3, 4 and $5 \mu \mathrm{g} / \mathrm{ml}$ for ibuprofen and 5, 10, 15, 20 and 25 $\mu \mathrm{g} / \mathrm{ml}$ for famotidine) were prepared. Six runs of each sample were analyzed using UV-Visible Scanning Spectrophotometer (UV-1800) of
Shimadzu scientific instruments, Japan at $221 \mathrm{~nm}$ for ibuprofen and $265 \mathrm{~nm}$ for famotidine (Pharmacopoeia, U.S., 2006 (a \& b). The average absorbance values of six runs of each concentration were plotted against respective drug concentrations and thus standard curve of ibuprofen and famotidine was produced.

Assay of ibuprofen and famotidine in fixed-dose combination IR tablets: Five formulated tablets were dispensed in a mortar and pestle and crushed towards fine powder. A portion equivalent to $10 \mathrm{mg}$ of each drug substances were poured into two different 100 $\mathrm{ml}$ volumetric flasks and made up to the mark with the diluting solution and sonicated for 10 minutes. No addition of organic solvents was required as both of the drugs were readily soluble in water (Pharmacopoeia, U.S., 2006 (c \& d). Followed by filtration through Whatman Filter Paper No. 41 (Whatman plc, UK) first few $\mathrm{ml}$ of filtrates were discarded and from the rest of the aliquots (concentration $100 \mu \mathrm{g} / \mathrm{ml}$ for both drug substances), 2 $\mathrm{ml}$ and $10 \mathrm{ml}$ filtrate from respective volumetric flasks of ibuprofen and famotidine was transferred to two separate $50 \mathrm{ml}$ volumetric flask and filled up to the mark with mobile phase and sonicated for 3 minutes respectively. With the analyzing concentration of $4 \mu \mathrm{g} / \mathrm{ml}$ for ibuprofen and $20 \mu \mathrm{g} / \mathrm{ml}$ for famotidine, absorbance was recorded for six runs of each concentration spectrophotometrically at respective wavelengths and drug content was calculated.

\section{Characterization of formulations for compatibility study.}

FTIR analysis: The FTIR spectrum of the active drugs and the crushed tablet powder, containing the drugs along with formulation aids, were recorded in the range of $600-4000 \mathrm{~cm}^{-1}$ using FTIR Spectrum Two ${ }^{\mathrm{TM}}$ L160000T of Perkin Elmer, USA.

TGA analysis: Under nitrogen flow of $10 \mathrm{ml} / \mathrm{min}$ thermogravimetric analysis was performed using Thermogravimetric Analyzer (TGA-50H) (Shimadzu, Japan). Approximately $5.0 \mathrm{mg}$ of drug samples and crushed powder of the formulated tablets were placed 
in a sealed aluminum cell and heated at a rate of $10{ }^{\circ} \mathrm{C} / \mathrm{min}$ up to $800^{\circ} \mathrm{C}$.

XRD analysis: Solubility and dissolution rate of a drug substance were greatly influenced by the degree of crystallinity. Hence, the crystalline nature of the drug substances before and after compression were studied by X-ray Diffractometer (XRD-6100) (Shimadzu, Japan) from a diffraction angle of 10-70 2-theta (deg.).

Surface morphology study by SEM: Particle morphology and surface topography of formulated tablets and placebo were revealed by SEM-8100FM of Shimadzu, crop. Japan at an accelerating voltage of $20 \mathrm{kV}$ and magnified at 500x and $1000 \mathrm{x}$ respectively.

Drug release studies: For determination of release kinetics of the formulated immediate-release tablets USP dissolution type II apparatus (Erweka, Germany) set at $50 \mathrm{rpm}$ (rotation per minutes) filled with dissolution medium of $\mathrm{pH} 7.2$ up to $900 \mathrm{ml}$ and maintained at $37 \pm 0.5^{\circ} \mathrm{C}$ was used (European patent application, 2012). At a specified time-intervals (05, $10,15,20,30$ and 45 minutes), $10 \mathrm{ml}$ of dissolution samples were collected for spectrophotometric analysis at specified detecting wavelength and an equal volume of aliquot samples were refilled with dissolution medium to maintain sink condition. After triplicate analysis at each time intervals, the results were averaged and the percentage of drug release was plotted against time and fitted into several mathematical models to get a notion about the release profile of the drugs from the formulations.

\section{Results and Discussion}

Flow properties of the granules: Generally, Angle of Repose less than 40, Compressibility index or Carr's index up to 20 and Hausner ratio value less than 1.25 are indicative parameters of fair to excellent flow properties of granule or powder blend (Pharmacopoeia, U.S., 2004). In this experiment, all 15 formulations indicated good flow property as the Carr's index was within the range of $11.894 \pm 1.013$ $19.872 \pm 1.927$, Hausner's ratio $1.135 \pm 0.096-1.248$ \pm 0.129 and Angle of Repose 27.35 \pm 0.031-38.33 \pm 0.016 (Table 3).

Table 3. Flow properties of the powder blend.

\begin{tabular}{cccccc}
\hline $\begin{array}{c}\text { Formulation } \\
\text { number }\end{array}$ & $\begin{array}{c}\text { Bulk density } \\
(\mathrm{gm} / \mathrm{ml})\end{array}$ & $\begin{array}{c}\text { Tapped density } \\
(\mathrm{gm} / \mathrm{ml})\end{array}$ & $\begin{array}{c}\text { Carr's index } \\
(\%)\end{array}$ & $\begin{array}{c}\text { Hausner's } \\
\text { ratio }\end{array}$ & $\begin{array}{c}\text { Angle of } \\
\text { repose }\end{array}$ \\
\hline F-1 & $0.314 \pm 0.019$ & $0.381 \pm 0.014$ & $17.560 \pm 1.107$ & $1.213 \pm 0.131$ & $37.41 \pm 0.020$ \\
F-2 & $0.317 \pm 0.008$ & $0.376 \pm 0.005$ & $15.754 \pm 2.152$ & $1.187 \pm 0.078$ & $32.18 \pm 0.013$ \\
F-3 & $0.298 \pm 0.015$ & $0.369 \pm 0.002$ & $19.290 \pm 1.118$ & $1.239 \pm 0.045$ & $35.29 \pm 0.027$ \\
F-4 & $0.326 \pm 0.019$ & $0.377 \pm 0.011$ & $13.570 \pm 1.294$ & $1.157 \pm 0.113$ & $33.16 \pm 0.011$ \\
F-5 & $0.332 \pm 0.007$ & $0.386 \pm 0.019$ & $13.867 \pm 1.227$ & $1.161 \pm 0.074$ & $38.33 \pm 0.016$ \\
F-6 & $0.300 \pm 0.016$ & $0.372 \pm 0.015$ & $19.225 \pm 2.379$ & $1.238 \pm 0.125$ & $34.57 \pm 0.023$ \\
F-7 & $0.305 \pm 0.018$ & $0.374 \pm 0.004$ & $18.367 \pm 1.281$ & $1.225 \pm 0.038$ & $32.69 \pm 0.024$ \\
F-8 & $0.325 \pm 0.011$ & $0.383 \pm 0.008$ & $15.254 \pm 1.529$ & $1.180 \pm 0.021$ & $30.11 \pm 0.012$ \\
F-9 & $0.318 \pm 0.010$ & $0.361 \pm 0.001$ & $11.894 \pm 1.013$ & $1.135 \pm 0.096$ & $28.62 \pm 0.016$ \\
F-10 & $0.312 \pm 0.003$ & $0.379 \pm 0.016$ & $17.763 \pm 1.138$ & $1.216 \pm 0.112$ & $31.27 \pm 0.010$ \\
F-11 & $0.334 \pm 0.012$ & $0.380 \pm 0.017$ & $12.127 \pm 2.738$ & $1.138 \pm 0.061$ & $36.31 \pm 0.022$ \\
F-12 & $0.315 \pm 0.017$ & $0.375 \pm 0.007$ & $16.107 \pm 2.041$ & $1.192 \pm 0.143$ & $36.17 \pm 0.018$ \\
F-13 & $0.301 \pm 0.001$ & $0.364 \pm 0.012$ & $17.219 \pm 1.611$ & $1.208 \pm 0.052$ & $27.35 \pm 0.031$ \\
F-14 & $0.330 \pm 0.002$ & $0.387 \pm 0.003$ & $14.749 \pm 2.240$ & $1.173 \pm 0.041$ & $29.73 \pm 0.250$ \\
F-15 & $0.296 \pm 0.013$ & $0.370 \pm 0.010$ & $19.872 \pm 1.927$ & $1.248 \pm 0.129$ & $36.45 \pm 0.015$ \\
\hline
\end{tabular}

Physical properties of formulated tablets: The physical properties of the formulated tablets were determined according to the aforementioned procedures mentioned in the materials and methods section. The diameters of the tablets were $12 \pm 0.002$ $\mathrm{mm}$, thickness $1.98 \pm 0.05 \mathrm{~mm}$, hardness or crushing 
strength $4.10 \pm 0.03$ to $8.52 \pm 0.07 \mathrm{~kg} / \mathrm{cm}^{2}$, average weight $798.72 \pm 3.85$ to $803.41 \pm 4.73 \mathrm{gm}$ and friability were $0.15-0.98 \%$. For all 15 formulations, the contents of active drug substance in a weighed amount of powder blend were found from 97.31 $103.85 \%$ and $99.28-100.51 \%$ for ibuprofen and famotidine respectively. All physical properties of the formulated tablets of 15 different formulations exhibited acceptable compliance with the compendial specifications (Chandrasekaran, 2011).

\section{Compatibility studies}

FTIR spectrum of pure Ibuprofen demonstrated respective peaks at $2951.95 \mathrm{~cm}^{-1}$ (Alkyl C-H Stretch), $2869.16 \mathrm{~cm}^{-1}$ (Carboxylic Acid O-H Stretch) and $1702.26 \mathrm{~cm}-1$ (Carboxylic Acid C=O Stretch) while Famotidine at $3504.48 \mathrm{~cm}^{-1}$ (Amide N-H Stretch), $3398.31 \mathrm{~cm}^{-1}$ (Amine N-H Stretch) $1530.93 \mathrm{~cm}^{-1}$ (Aromatic $\mathrm{C}=\mathrm{C}$ Bending). The preservation of the original peaks of the APIs and the absence of any new peaks in the crushed tablet powder indicate, no polymorphic change took place during tablet formulation with the specified excipients. Additionally, at molecular level, no significant interaction between the drugs and the excipients is noted as there is no shifts in the wavenumbers of the FTIR peaks (Figure 1).

TGA was performed to quantitate mass loss along with the constant increment of heat and for revealing thermal stability regions of the experimented formulation. This study illustrated about 3\%, 3.17\% and 6.6\% mass loss took place for ibuprofen, famotidine and crushed powder of the finished tablet at $133.88^{\circ} \mathrm{C}, 151.81^{\circ} \mathrm{C}$ and $153.11^{\circ} \mathrm{C}$ respectively (Figure 2). These results help us to infer about thermo sensitivity of the tested formulations and wet granulation (where drying phase is a must) and other thermal exposure should be minimized for preparing pharmaceutical dosages forms containing these drug substances.

XRD study of the experimented formulation revealed smaller peak heights in crushed tablet powder which results due to reduced crystal size and crystallinity as compared to formulation blend before compression. Most importantly, no peaks were disappeared and exhibited sharp peaks at diffraction angles at $2 \theta$ of $16.515,17.635,19.027,19.465$, $20.134,22.294^{\circ}$ (Figure 3).

SEM analysis of the crushed tablet powder and the placebo revealed amorphous surface morphology of the formulated tablets and plausible penetration of APIs into the pores of the tablets as the distinguishable presence of ibuprofen and famotidine was absent in crushed tablet powder and discernible difference was apparent between crushed tablet powder and placebo (Figure 4).

Screening of formulations through DoE approach: This study was meant to evaluate the effects of several formulation aids on the preparation of directly compressed ibuprofen and famotidine containing immediate-release dosages form by considering the release kinetics of the APIs from the formulation matrix. To evaluate this, DoE was implemented, where different concentrations of three formulation excipients were considered and their effects were reflected on friability and disintegration time.

Before focusing on the statistical approach, initial screening was done through evaluating friability and disintegration time of each of the formulations to infer whether they comply with the compendial specifications of these two physical properties of tablet dosages forms (Rudnic and Schwartz, 1990; Pharmacopoeia, B., 2007).

Here in table 4, all 15 formulations passed the friability test but 04 formulations (F-1, F-5, F-12, F15) out of 15 failed to meet the disintegration time limit so, the rest of the 11 formulations were selected to implement the DoE approach by taking into consideration the predicted (generated by the software) and the experimented values of the dependent variables.

The contour diagram and the 3D surface response diagram provided in figure 5 indicate the best formulations showing friability and disintegration time data close to experimental results. The equation presented in table 5 could be used to predict the responses of each actual component for given levels. In this context, the combined effects of 

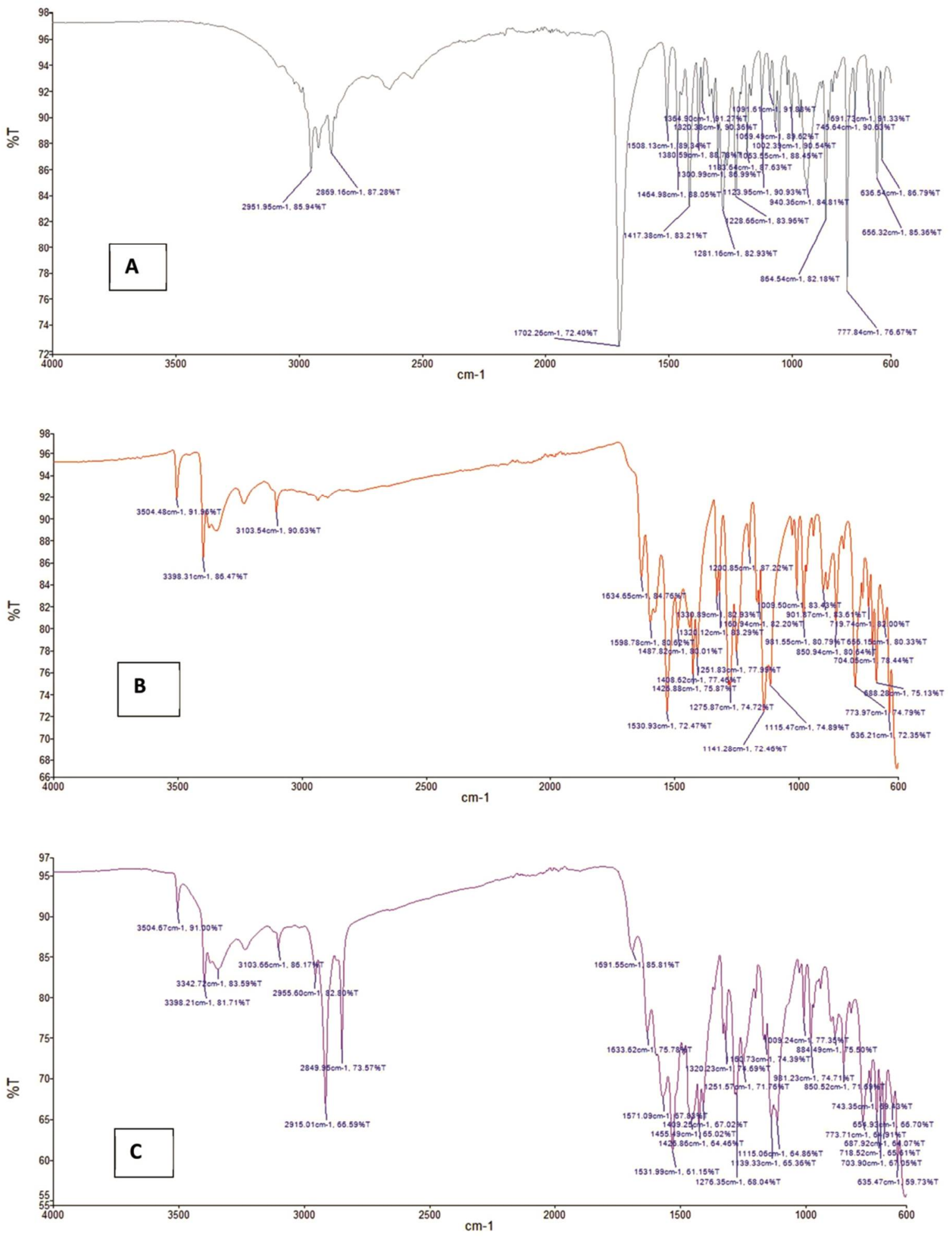

Figure 1. FTIR spectra of (A) Ibuprofen, (B) Famotidine and (C) Crushed tablet powder. 

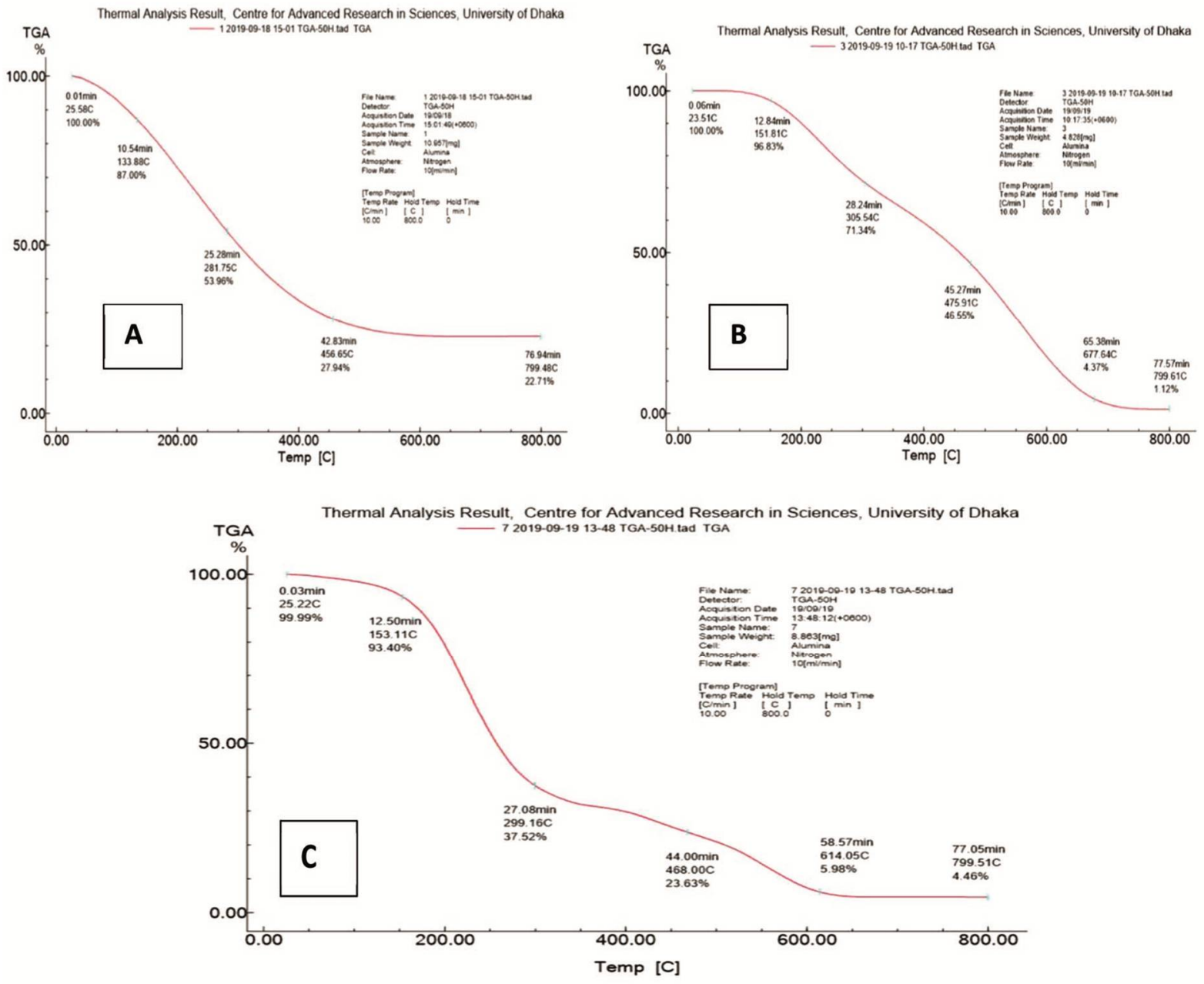

Figure 2. TGA Thermogram of (A) Ibuprofen, (B) Famotidine and (C) Crushed tablet powder.
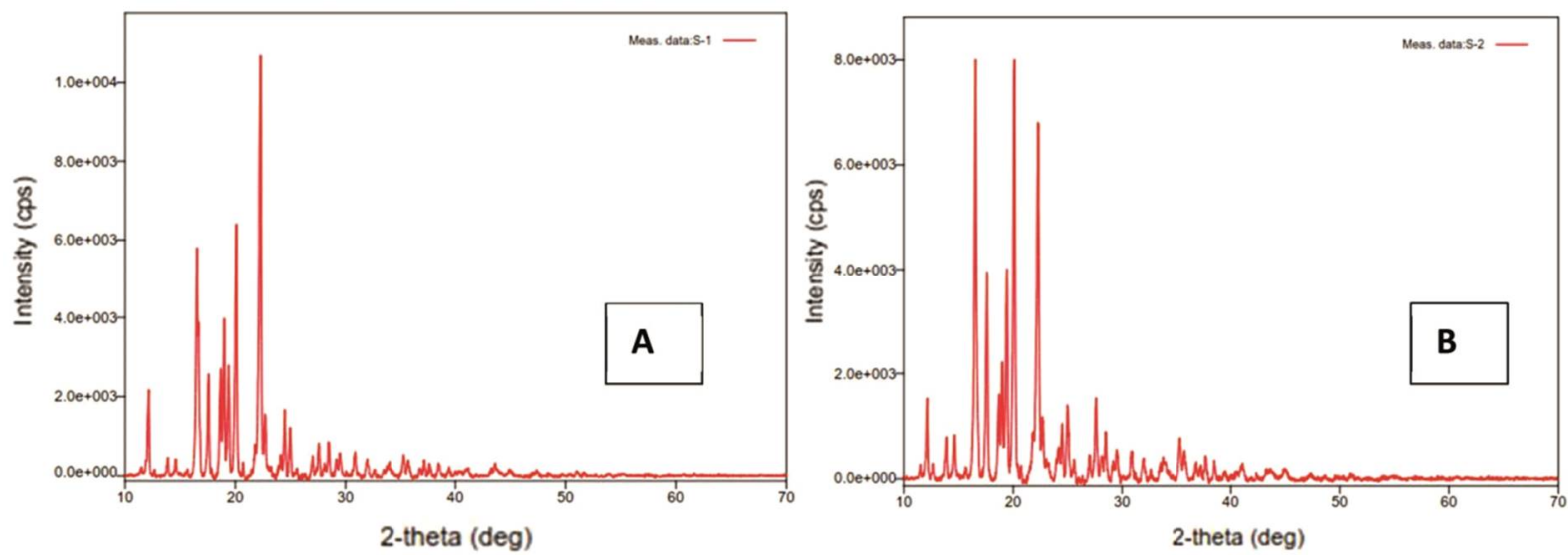

Figure 3. XRD spectrum of (A) formulation blend before compression and (B) crushed tablet powder after compression 

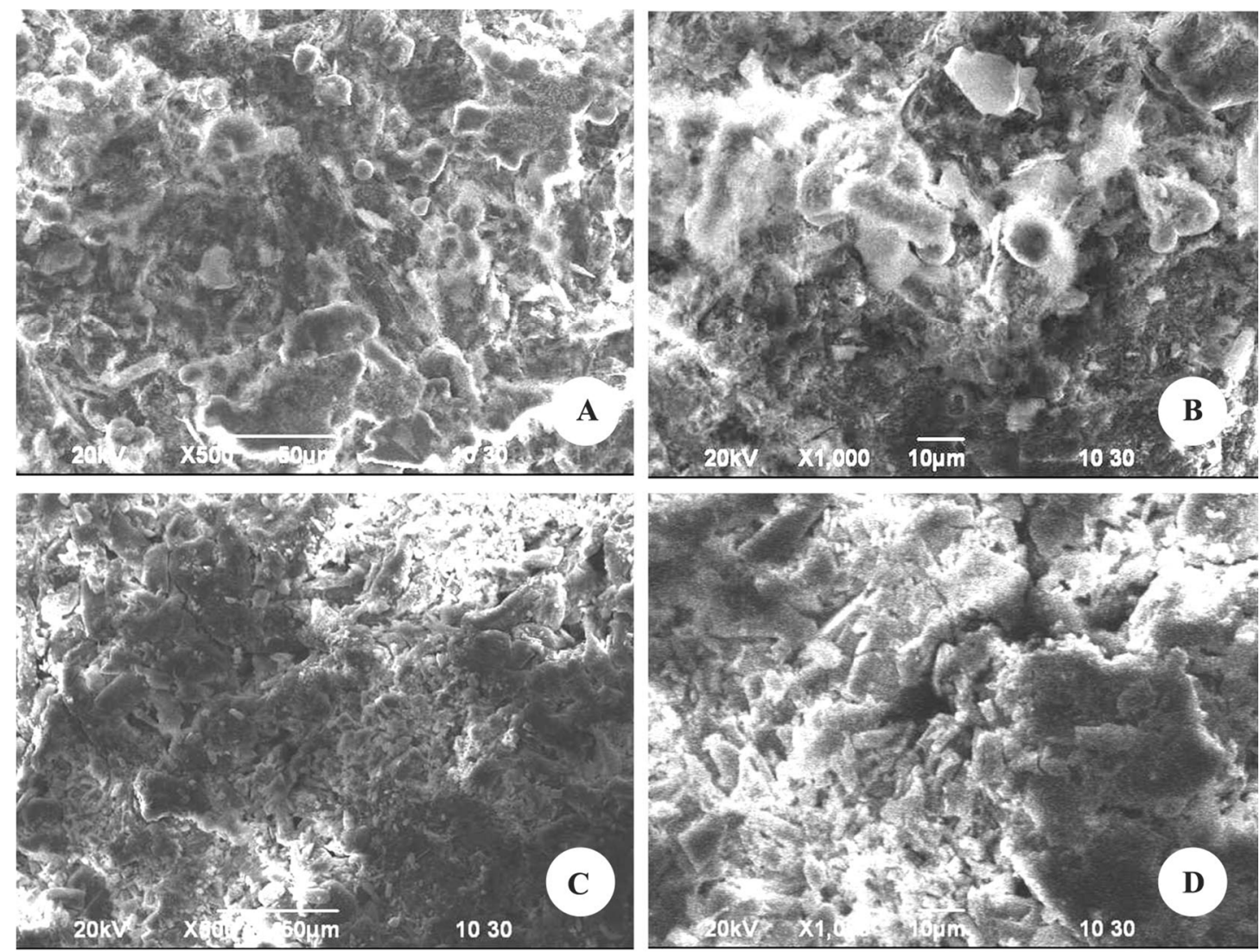

Figure 4. SEM image of (A \& B) crushed tablet powder and (C \& D) placebo, at different magnification.

Table 4. Friability and disintegration time of the experimented formulations.

\begin{tabular}{ccc}
\hline $\begin{array}{c}\text { Formulation } \\
\text { number }\end{array}$ & Friability (\%) & $\begin{array}{c}\text { Disintegration time } \\
\text { (min) }\end{array}$ \\
\hline F-1 & 0.44 & 1.8 \\
F-2 & 0.24 & 7.2 \\
F-3 & 0.32 & 10.9 \\
F-4 & 0.23 & 7.5 \\
F-5 & 0.30 & 20.5 \\
F-6 & 0.39 & 11.0 \\
F-7 & 0.21 & 7.2 \\
F-8 & 0.35 & 7.2 \\
F-9 & 0.34 & 6.1 \\
F-10 & 0.38 & 8.5 \\
F-11 & 0.45 & 5.7 \\
F-12 & 0.37 & 2.0 \\
F-13 & 0.30 & 8.3 \\
F-14 & 0.32 & 8.4 \\
F-15 & 0.26 & 2.5 \\
\hline
\end{tabular}

PVP-K30, Avicel PH-102 and Starch-1500 were studied to provide a design space with dependent variables within the acceptable range i.e. friability $<1 \%$ and disintegration time between 3 to $15 \mathrm{~min}$. The Figure 6 (yellow region) indicates the acceptable design space which was taken for D-optimal design conducted through design expert version 12 software to generate predicted values for friability and disintegration time as shown in Table 6. Increasing the concentration of binder and PVP-K30, it was assumed that the friability would be lower and the disintegration time would be higher. Here we found only seven formulations (F-3, F-6, F-8, F-9, F-10, F13 and F-14) having friability and disintegration time of predicted value very close to the experimental value. For the other 4 formulations (F-2, F-4, F-7 and F-11) their differences were so high that, there was less chance to get a successful formulation from those. After that, those seven formulations were considered for further In-vitro dissolution and kinetic studies. 


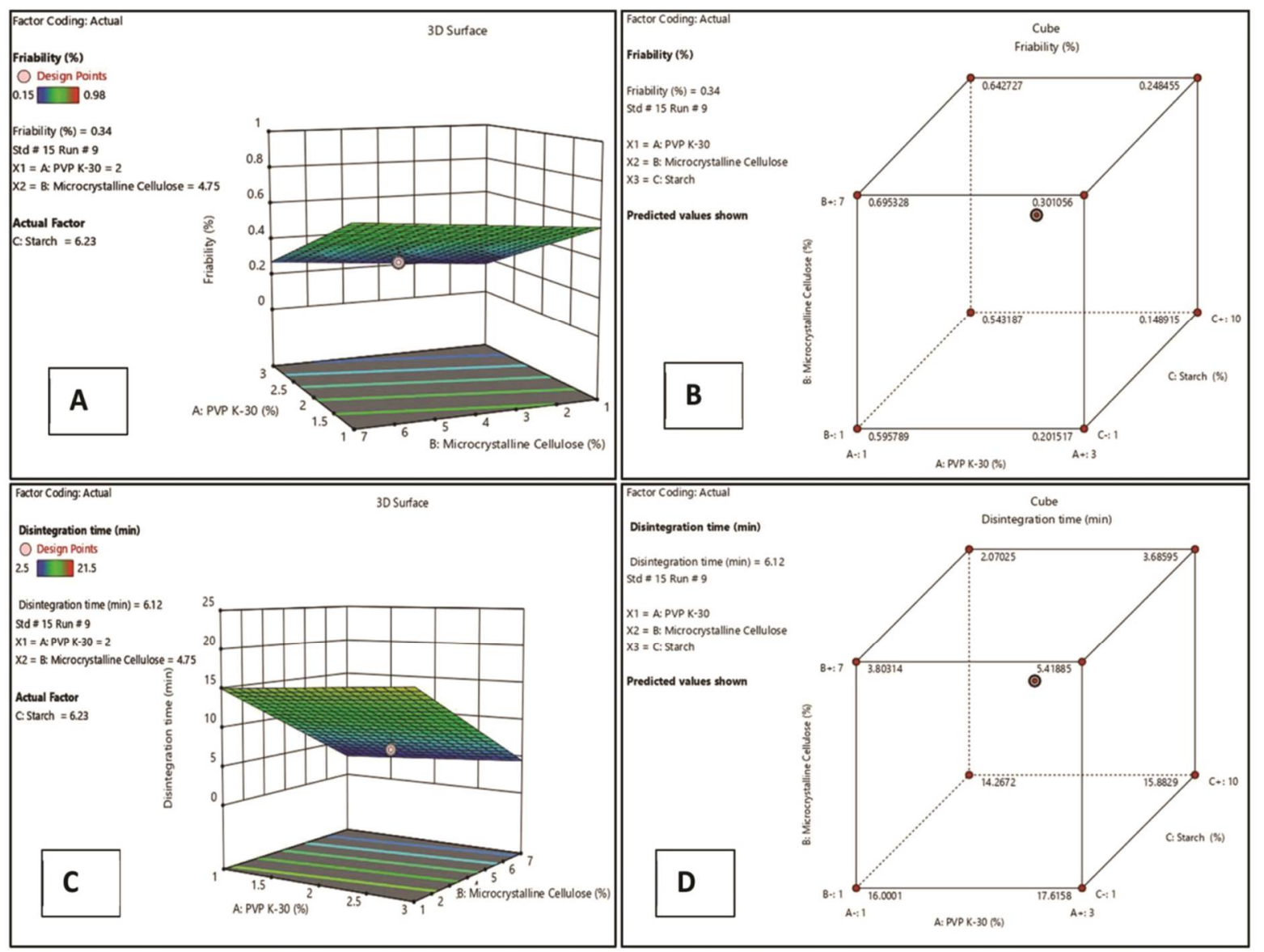

Figure 5. (A \& C) Contour Diagram and (B \& D) 3D Surface Response Diagram indicating optimization and prediction of friability and disintegration time respectively.
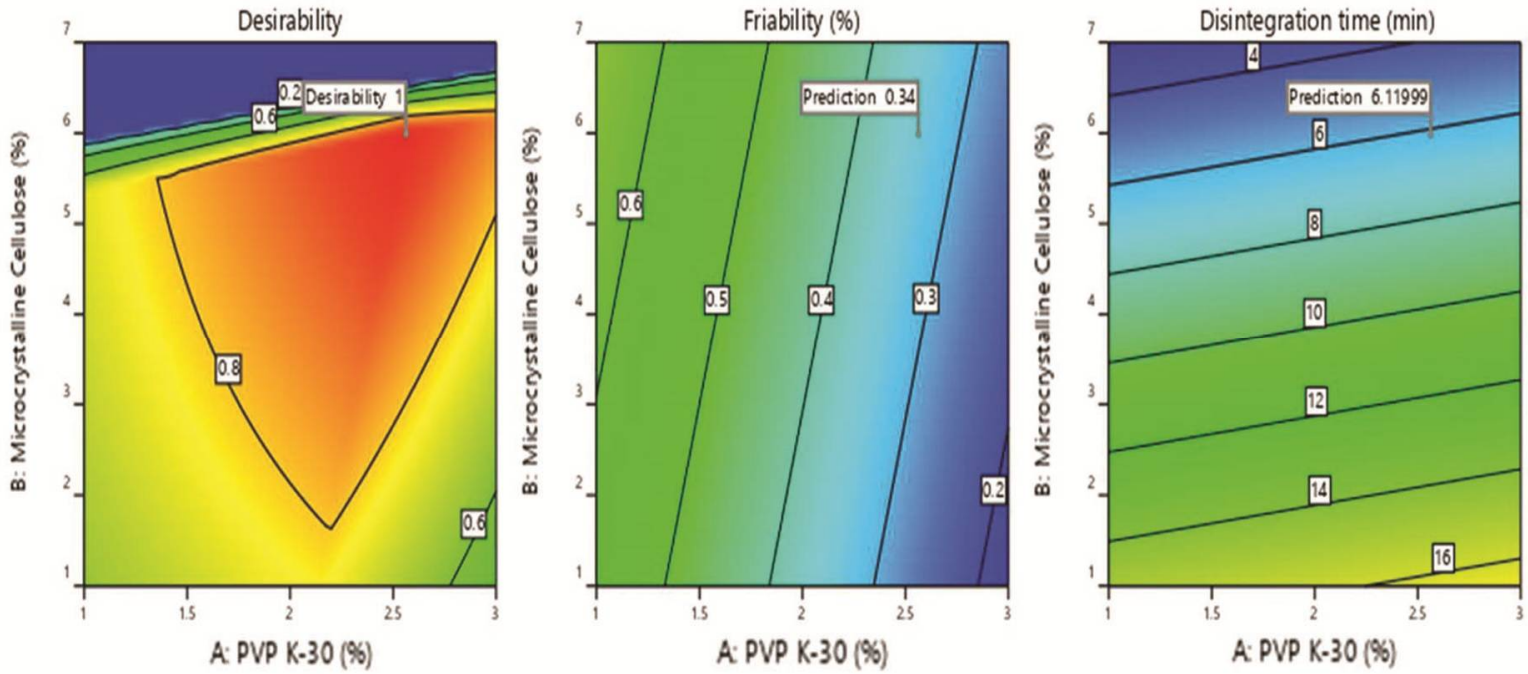

Figure 6. Effects of combined independent variables on simultaneous prediction of friability and disintegration time. 
Table 5. Equation for friability and disintegration time in terms of actual components.

\begin{tabular}{llc}
\hline Friability & \multicolumn{1}{c}{ Components } & Disintegration time \\
\hline-22.66508 & $*$ PVPK30 & +4.89221 \\
-10.78748 & $*$ Starch1500 & +1.02884 \\
-3.31625 & $*$ MicrocrystallinePH102 & +3.77274 \\
+2.65500 & $*$ PVP K30 Starch1500 & -0.33147 \\
+2.67523 & $*$ PVP K30* MicrocrystallinePH102 & -0.33317 \\
+1.47956 & $*$ Starch 1500* MicrocrystallinePH102 & -0.31655 \\
-0.35247 & *PVPK30*Starch1500*MCC-102 & -0.32293 \\
\hline
\end{tabular}

Table 6. Predictions from models and experimented results.

\begin{tabular}{cccccccc}
\hline \multirow{2}{*}{$\begin{array}{c}\text { Formulation } \\
\text { number }\end{array}$} & $\begin{array}{c}\text { PVP K30 } \\
(\%)\end{array}$ & $\begin{array}{c}\text { Avicel PH } \\
102(\%)\end{array}$ & $\begin{array}{c}\text { Starch } \\
\text { 1500 }(\%)\end{array}$ & $\begin{array}{l}\text { Friability } \\
(\%)\end{array}$ & $\begin{array}{c}\text { Disintegration } \\
\text { time (min) }\end{array}$ & $\begin{array}{l}\text { Friability } \\
(\%)\end{array}$ & $\begin{array}{c}\text { Disintegration } \\
\text { time (min) }\end{array}$ \\
\hline F-2 & 3 & 1 & 10 & 0.34 & $8.2 \geq$ & 0.24 & 7.2 \\
F-3 & 2.75 & 4 & 5.5 & 0.34 & $8.2 \geq$ & 0.32 & 10.9 \\
F-4 & 1.5 & 4 & 5.5 & 0.34 & $8.2 \geq$ & 0.23 & 7.5 \\
F-6 & 1 & 1 & 10 & 0.34 & $8.2 \geq$ & 0.39 & 11 \\
F-7 & 3 & 7 & 10 & 0.34 & $8.2 \geq$ & 0.21 & 7.2 \\
F-8 & 2 & 4 & 9.5 & 0.34 & $6.1 \geq$ & 0.35 & 7.2 \\
F-9 & 2 & 4.75 & 6.5 & 0.34 & $6.1 \geq$ & 0.34 & 6.1 \\
F-10 & 1 & 7 & 10 & 0.34 & $6.1 \geq$ & 0.38 & 8.5 \\
F-11 & 2 & 4 & 6.5 & 0.34 & $6.1 \geq$ & 0.45 & 5.7 \\
F-13 & 3 & 7 & 1 & 0.34 & $7.3 \geq$ & 0.30 & 8.3 \\
F-14 & 1 & 7 & 1 & 0.34 & $7.4 \geq$ & 0.32 & 8.4 \\
\hline
\end{tabular}

In vitro dissolution and kinetic studies: Drug release kinetics and mechanism of drug release from initial screened out 7 tablet formulations (F-3, F-6, F8, F-9, F-10, F-13 and F-14) were assessed via invitro drug release studies using $\mathrm{pH} 7.2$ phosphate buffer as dissolution medium. Initially, a standard curve for both APIs were prepared with a satisfactory regression coefficient $\left(\mathrm{R}^{2}\right)$ value of 0.989 and 0.987 for ibuprofen and famotidine respectively (Figure 7). Then in vitro dissolution characteristics of ibuprofen and famotidine for all 7 formulations were compared (Figure 8 and 9).

For this research it was found that, within 15 minutes about $81 \%$ of drugs were released from the formulations (F-6, F-8, F-9, F-10, F-13 and F-14) with a deviation in F-3, where only $69 \%$ of drugs release were observed but later on, it gained its pace and at 20 minutes it released around $92 \%$ of the APIs similar with the other formulations where $\%$ of drug release were found ranging 95-97\%. Furthermore, about $99 \%$ of drugs release were observed for both ibuprofen and famotidine from selected 7 fixed-dose combination formulations at 45 minutes. With the increase of starch concentration from mid-range towards higher value drug release percentage gradually increase but this rise in concentration drastically affects the tablet's crushing strength (F-6, F-8 and F-10). Also, with the higher value of PVPK30 tablet's strength decreases, which is evident with F-3. With a concentration slightly higher than the mid values of the respective formulation excipients, tablets showed better drugs release pattern as well as better strength for further study which is found in F9. 
Among the screened out 7 formulations, hardness test was performed and only three of the formulations meet the acceptance criteria (hardness value $8.52 \pm 0.07,7.92 \pm 0.02$ and $8.31 \pm 0.01 \mathrm{~kg} / \mathrm{cm}^{2}$ for F-9, F-13 and F-14 respectively) while the others failed to meet the requirements $(4.10 \pm 0.03$, $4.24 \pm 0.05,4.13 \pm 0.02$ and $4.03 \pm 0.18 \mathrm{~kg} / \mathrm{cm}^{2}$ for F-3, F-6, F-8 and F-10 respectively). If the hardness of tablet is very high, the tablet may not disintegrate at specified time to meet dissolution criteria and on the other hand, subsequent processing such as coating or packaging and shipping operations may become impossible to handle if tablet is very soft. Therefore, the importance of having a suitable hardness value for oral tablet dosages form is undeniable.

All the release data achieved from these selected 07 formulations were coded in distinct kinetics models such as Zero order (Harland et al., 1988), First order, Higuchi (Higuchi, 1963), KorsmeyerPeppas (Korsmeyer and Peppas, 1983) and HixsonCrowell (Hixson and Crowell, 1931) and the drug release mechanism was identified through graphical determination of correlation coefficients. Among the screened-out formulations, apart from F-9 others showed non-fickian or anomalous transport of drug release from tablets for ibuprofen, which mean the mechanism of drug release in those formulations is

Table 7. Model dependent kinetic analysis of ibuprofen from screened out formulations.

\begin{tabular}{|c|c|c|c|c|c|c|c|c|c|c|c|c|}
\hline \multirow{2}{*}{$\begin{array}{c}\text { Formu- } \\
\text { lation } \\
\text { No. }\end{array}$} & \multicolumn{2}{|c|}{ Zero order } & \multicolumn{2}{|c|}{ First order } & \multicolumn{2}{|c|}{ Higuchi } & \multicolumn{2}{|c|}{ Hixon-Crowell } & \multicolumn{2}{|c|}{$\begin{array}{l}\text { Korsmeyer- } \\
\text { Peppas }\end{array}$} & \multirow[t]{2}{*}{$\begin{array}{c}\text { Best fit } \\
\text { model }\end{array}$} & \multirow[t]{2}{*}{ Release mechanism } \\
\hline & $\mathrm{R}^{2}$ & $\mathrm{~K}_{0}$ & $\mathrm{R}^{2}$ & $\mathrm{~K}_{1}$ & $\mathrm{R}^{2}$ & $\mathrm{~K}_{\mathrm{h}}$ & $\mathrm{R}^{2}$ & $\mathrm{~K}_{\mathrm{hc}}$ & $\mathrm{R}^{2}$ & $\mathrm{n}$ & & \\
\hline F-3 & 0.779 & 2.318 & 0.962 & -0.110 & 0.883 & 15.68 & 0.894 & -0.078 & 0.875 & 0.795 & $\begin{array}{l}\text { First } \\
\text { Order }\end{array}$ & $\begin{array}{l}\text { Non-Fickian /anomalous } \\
\text { transport }\end{array}$ \\
\hline F-6 & 0.667 & 2.008 & 0.942 & -0.126 & 0.894 & 15.26 & 0.863 & -0.083 & 0.829 & 0.721 & $\begin{array}{l}\text { First } \\
\text { Order }\end{array}$ & $\begin{array}{l}\text { Non-Fickian /anomalous } \\
\text { transport }\end{array}$ \\
\hline F-8 & 0.685 & 2.076 & 0.977 & -0.158 & 0.892 & 15.72 & 0.887 & -0.092 & 0.848 & 0.512 & $\begin{array}{l}\text { First } \\
\text { Order }\end{array}$ & $\begin{array}{l}\text { Non-Fickian /anomalous } \\
\text { transport }\end{array}$ \\
\hline F-9 & 0.727 & 2.246 & 0.978 & -0.148 & 0.879 & 15.69 & 0.868 & -0.079 & 0.846 & 0.475 & $\begin{array}{l}\text { First } \\
\text { Order }\end{array}$ & Fickian transport \\
\hline F-10 & 0.721 & 2.281 & 0.957 & -0.144 & 0.858 & 15.85 & 0.873 & -0.088 & 0.834 & 0.738 & $\begin{array}{l}\text { First } \\
\text { Order }\end{array}$ & $\begin{array}{l}\text { Non-Fickian /anomalous } \\
\text { transport }\end{array}$ \\
\hline F-13 & 0.719 & 2.258 & 0.974 & -0.143 & 0.867 & 15.85 & 0.894 & -0.087 & 0.837 & 0.749 & $\begin{array}{l}\text { First } \\
\text { Order }\end{array}$ & $\begin{array}{l}\text { Non-Fickian /anomalous } \\
\text { transport }\end{array}$ \\
\hline F-14 & 0.710 & 2.232 & 0.965 & -0.129 & 0.858 & 15.67 & 0.875 & -0.080 & 0.822 & 0.686 & $\begin{array}{l}\text { First } \\
\text { Order }\end{array}$ & $\begin{array}{l}\text { Non-Fickian /anomalous } \\
\text { transport }\end{array}$ \\
\hline
\end{tabular}
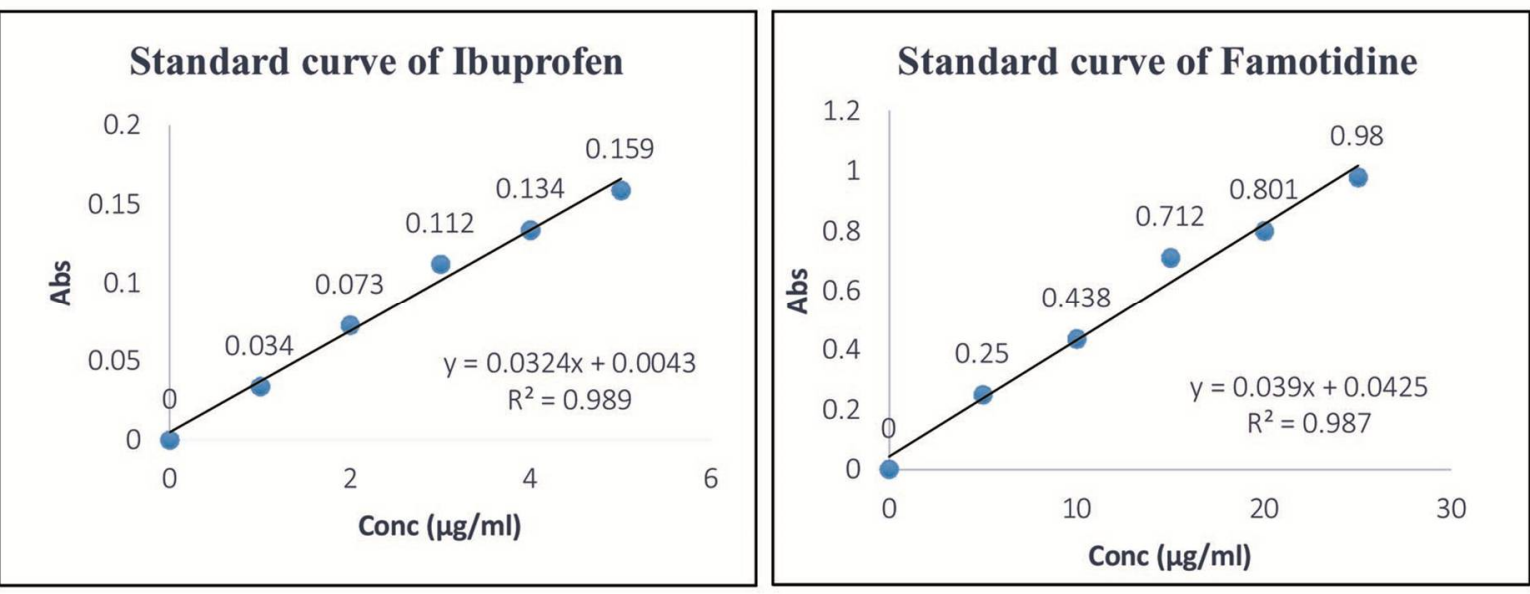

Figure 7. Standard Curve of ibuprofen and famotidine in $\mathrm{pH} 7.2$ phosphate buffer solution. 

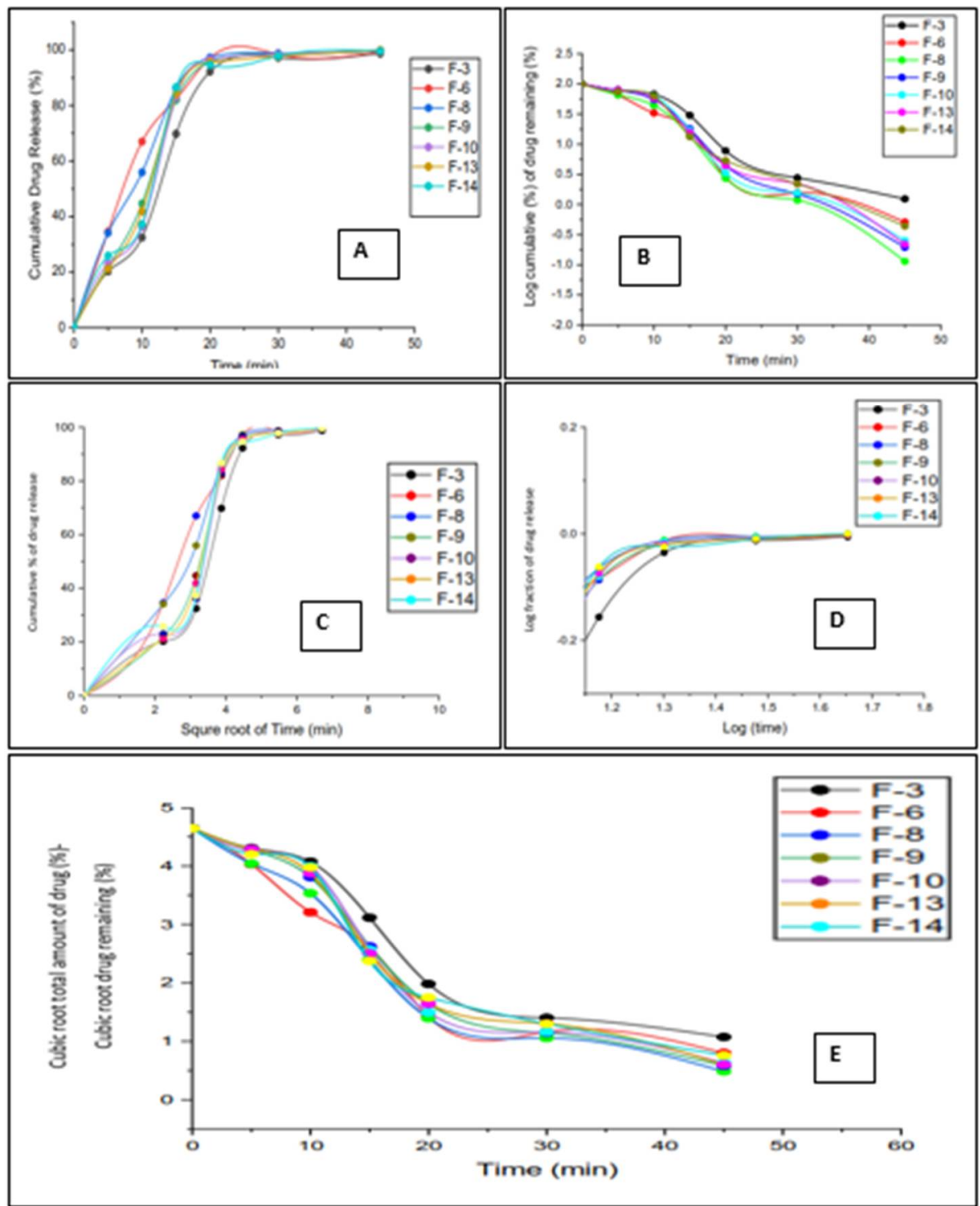

Figure 8. Drug release kinetics plots of ibuprofen (A) Zero-order plot, (B) First order plot, (C) Higuchi plot, (D) KorsmeyerPeppas plot and (E) Hixson-Crowell plot.

governed by diffusion and swelling. While in F-9 for ibuprofen and all formulations in terms of famotidine, fickian transport of drug release were experienced, which represent in those formulations drug release was governed by diffusion and solvent transport rate or diffusion is much greater than the process of polymeric chain relaxation (Bruschi, 2015). Respective results of model-dependent kinetic analysis and best-fitted model along with drugs release mechanism are depicted in table 7 and 8 for ibuprofen and famotidine respectively.

\section{Comparative dissolution with marketed product} and identification of best suitable experimental formulation: Because of the unavailability of similar fixed-dose products in Bangladesh, in this study single tablet dosages form of ibuprofen $400 \mathrm{mg}$ and famotidine $20 \mathrm{mg}$ tablet (manufactured in 2020 and expired in 2022) of renowned pharmaceutical company were considered as market product or comparator and \% drug release against time was compared with finally selected 3 experimental formulations (F-9, F-13 and F-14). Comparative 
dissolution study was conducted in aforementioned dissolution ambience where similar drug release for test and comparator product was observed for ibuprofen but in terms of famotidine experimented products showed superior dissolution profile compared to market product since $80 \%$ of drug release was observed within 6-7 minutes for experimented products whereas it took about 10 minutes for the marketed one (Figure 10).
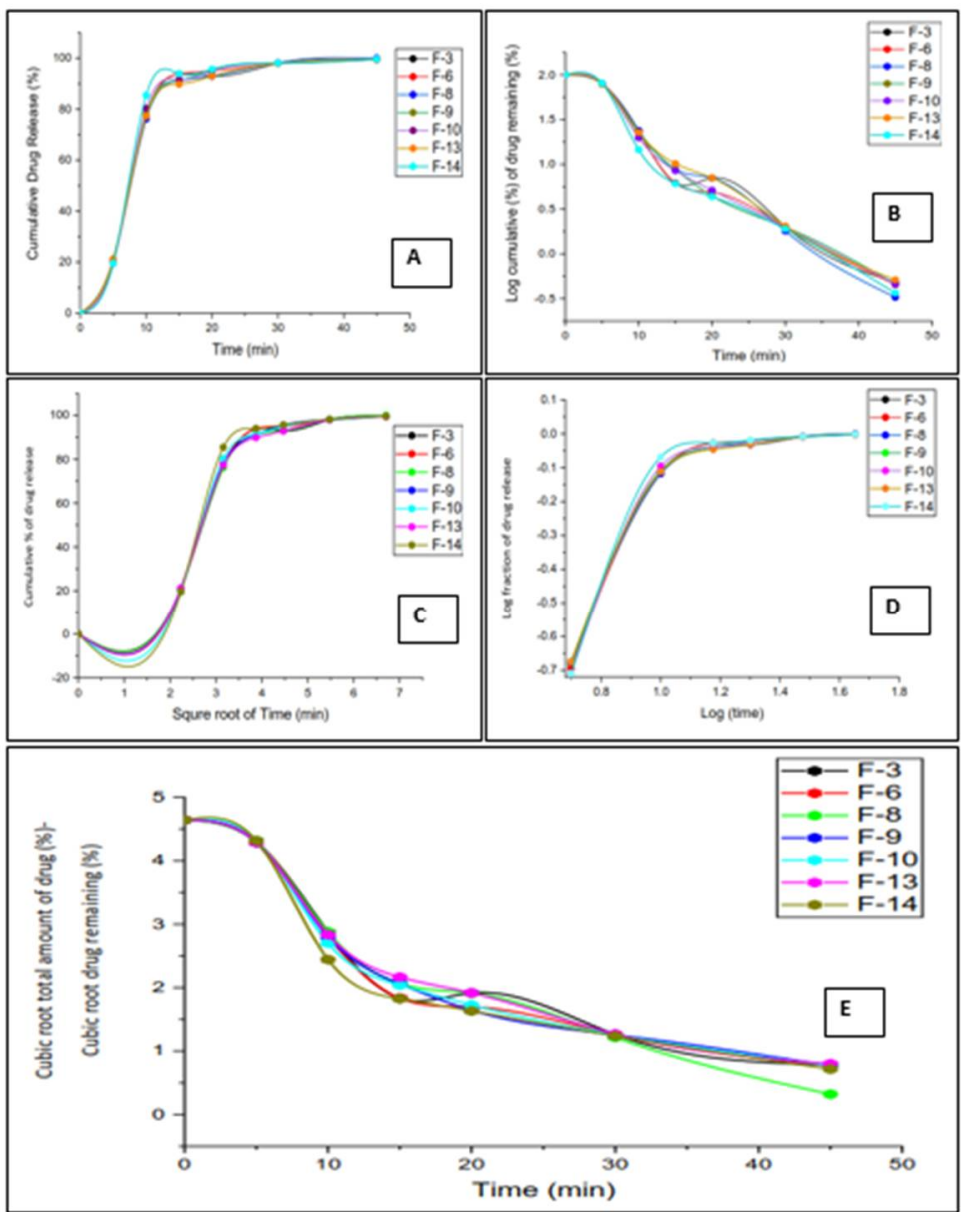

Figure 9. Drug release kinetics plots of famotidine (A) Zero-order plot, (B) First order plot, (C) Higuchi plot, (D) Korsmeyer-Peppas plot and (E) Hixson-Crowell plot.
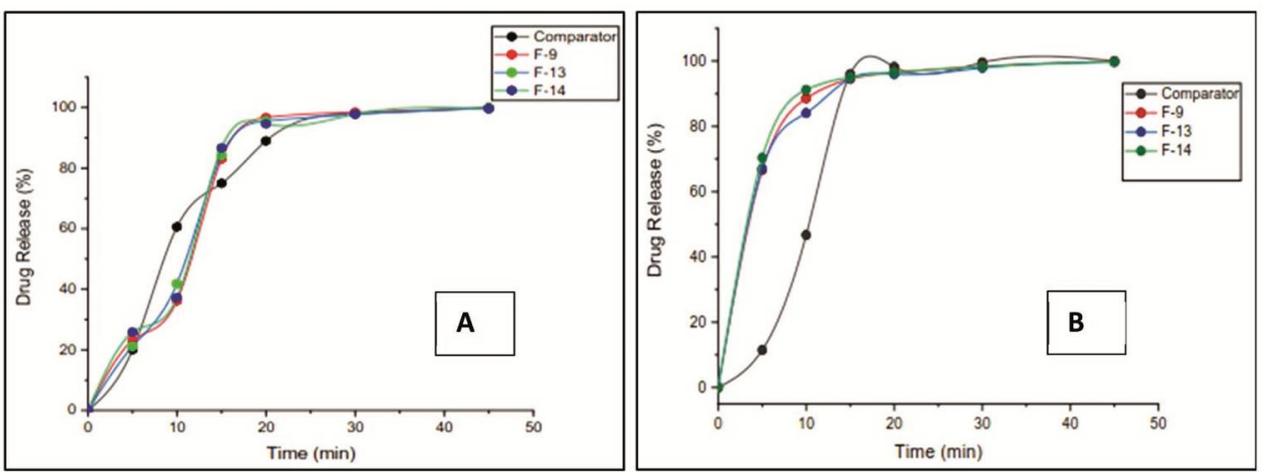

Figure 10. Comparison of dissolution profile for (A) ibuprofen and (B) famotidine between marketed and finally selected experimented products. 
Table 8. Model dependent kinetic analysis of famotidine from screened out formulations.

\begin{tabular}{|c|c|c|c|c|c|c|c|c|c|c|c|c|}
\hline \multirow[t]{2}{*}{$\begin{array}{c}\text { Formulation } \\
\text { No. }\end{array}$} & \multicolumn{2}{|c|}{ Zero order } & \multicolumn{2}{|c|}{ First order } & \multicolumn{2}{|c|}{ Higuchi } & \multicolumn{2}{|c|}{ Hixon-Crowell } & \multicolumn{2}{|c|}{$\begin{array}{c}\text { Korsmeyer- } \\
\text { Peppas }\end{array}$} & \multirow[t]{2}{*}{$\begin{array}{l}\text { Best fit } \\
\text { model }\end{array}$} & \multirow[t]{2}{*}{$\begin{array}{c}\text { Release } \\
\text { mechanism }\end{array}$} \\
\hline & $\mathrm{R}^{2}$ & $\mathrm{~K}_{0}$ & $\mathrm{R}^{2}$ & $\mathrm{~K}_{1}$ & $\mathrm{R}^{2}$ & $\mathrm{~K}_{\mathrm{h}}$ & $\mathrm{R}^{2}$ & $\mathrm{~K}_{\mathrm{hc}}$ & $\mathrm{R}^{2}$ & $\mathrm{n}$ & & \\
\hline F-3 & 0.4619 & 2.476 & 0.9728 & -0.122 & 0.763 & 15.65 & 0.748 & -0.081 & 0.637 & 0.180 & First Order & $\begin{array}{l}\text { Fickian } \\
\text { transport }\end{array}$ \\
\hline F-6 & 0.4375 & 2.015 & 0.9453 & -0.123 & 0.748 & 15.80 & 0.738 & -0.082 & 0.705 & 0.164 & First Order & $\begin{array}{l}\text { Fickian } \\
\text { transport }\end{array}$ \\
\hline F-8 & 0.4437 & 2.061 & 0.8596 & -0.174 & 0.756 & 15.93 & 0.832 & -0.091 & 0.834 & 0.161 & First Order & $\begin{array}{l}\text { Fickian } \\
\text { transport }\end{array}$ \\
\hline F-9 & 0.4377 & 2.046 & 0.8353 & -0.124 & 0.749 & 14.52 & 0.922 & -0.068 & 0.846 & 0.194 & First Order & $\begin{array}{l}\text { Fickian } \\
\text { transport }\end{array}$ \\
\hline F-10 & 0.465 & 2.045 & 0.8981 & -0.123 & 0.774 & 15.53 & 0.824 & -0.080 & 0.789 & 0.195 & First Order & $\begin{array}{l}\text { Fickian } \\
\text { transport }\end{array}$ \\
\hline F-13 & 0.4788 & 2.047 & 0.9679 & -0.122 & 0.786 & 15.44 & 0.795 & -0.079 & 0.841 & 0.186 & First Order & $\begin{array}{l}\text { Fickian } \\
\text { transport }\end{array}$ \\
\hline F-14 & 0.4346 & 2.017 & 0.9621 & -0.126 & 0.747 & 15.27 & 0.878 & -0.077 & 0.770 & 0.185 & First Order & $\begin{array}{l}\text { Fickian } \\
\text { transport }\end{array}$ \\
\hline
\end{tabular}

After that, identification of optimized experimented formulation was executed by calculating the potency of respective formulations, where F-9 showed the highest potency $(103.85 \%$ for ibuprofen and $100.51 \%$ for famotidine) and F-13 and F-14 exhibited $97.31 \%$ and $98.26 \%$ for ibuprofen and $99.67 \%$ and $99.28 \%$ for famotidine respectively.

\section{Conclusions}

Ibuprofen and Famotidine Fixed-Dose Combination (FDC) tablet formulations were developed in this study by using Design Expert $^{\circledR}$ software (version 12) through quality testing assessment. Performing all the experiments the best selected three formulations were compared to the market product in terms of dissolutions in $\mathrm{pH} 7.2$ phosphate buffer. Ibuprofen showed a similar drug release rate but famotidine showed superiority in the developed FDC product compared to market product. In terms of potency, formulation F-9 (PVP-K30 2\%, Avicel PH-102 4.45\% and Starch-1500 6.5\%) illustrated higher potency (103.85\% for ibuprofen and $100.51 \%$ for famotidine) than others. This formulation also exhibited faster disintegration time (6.1 minutes) and friability $(0.34 \%)$ with a suitable hardness value of $8.52 \pm 0.07$ over other formulations. Based on the results obtained from this study, it is evident that considerably slightly higher use of the specified excipients from their mid-range values considered in this experiment showed better and acceptable tablet properties, while the use of extreme values of those could not meet the superiority. So, to simplify treatment regimens and improving patient adherence to co-therapy, the production of local oral tablets containing NSAIDs and gastro-protectant is inevitable to diminish the gastrointestinal toxicity events associated with the indifferent use of NSAIDs in Bangladesh. However, it is essential from a biopharmaceutical viewpoint to arrange extensive in vitro in vivo correlation (IVIVC) studies on similar formulations.

\section{Conflict of interest}

The authors declare no conflict of interest.

\section{References}

AAT Bioquest, Inc. 2021. Potassium phosphate (pH 5.8 to 8.0). This article was retrieved from https://www. aatbio.com/resource/buffer-preparation-and-recipes/ potassium-phosphate-ph-5-8-to-8-0.

Al-Saeed, A. 2011. Gastrointestinal and cardiovascular risk of nonsteroidal anti-inflammatory drugs. Oman Med. J. 26, p.385.

Bello, A.E. 2012. DUEXIS® (ibuprofen $800 \mathrm{mg}$, famotidine $26.6 \mathrm{mg}$ ): A new approach to gastroprotection for patients with chronic pain and inflammation who require treatment with a nonsteroidal anti-inflammatory drug. Ther. Adv. Musculoskeletal Dis. 4, 327-339. 
Bhutani, H., Kurmi, M., Singh, S., Beg, S. and Singh, B. 2004. Quality by design (QbD) in analytical sciences: an overview. Qual. Assur. 3, 39-45.

Bruschi, M.L. 2015. In: Strategies to modify the drug release from pharmaceutical systems. Woodhead Publishing, Chapter 5- Mathematical models of drug release, pp. 63-86.

Chandrasekaran, A.R. 2011. Tablet assessments tests in pharmaceutical industry. Anal. Chem.: Indian J. 10, 581-589.

Deeks, E.D. 2013. Fixed-dose ibuprofen/famotidine: a review of its use to reduce the risk of gastric and duodenal ulcers in patients requiring NSAID therapy. Clin. Drug Invest. 33, 689-697.

European patent application EP 2438919 A1. 2012. Compositions comprising famotidine and ibuprofen as well as compositions comprising $25 \mathrm{mg}$ to $28 \mathrm{mg}$ famotidine. This article was retrieved from https://patents.google.com/patent/EP2438919A1/en.

Harland, R.S., Dubernet, C., Benoît, J.P. and Peppas, N.A. 1988. A model of dissolution-controlled, diffusional drug release from non-swellable polymeric microspheres. J. Controlled Release. 7, 207-215.

Higuchi, T. 1963. Mechanism of sustained action medication. Theoretical analysis of rate of release of solid drugs dispersed in solid matrices. J. Pharm. Sci. 52, 1145-1149.

Hixon, A.W and Crowell, J.H. 1931. Dependence of reaction velocity upon surface and agitation (I) theoretical consideration. Ind. Eng. Chem. 23, 923931.

Jackson, M.A., Goodrich, J.K., Maxan, M.E., Freedberg, D.E., Abrams, J.A., Poole, A.C., Sutter, J.L., Welter, D., Ley, R.E., Bell, J.T. and Spector, T.D. 2016. Proton pump inhibitors alter the composition of the gut microbiota. Gut, 65, 749-756.

Karim, R. and Banoo, R. 2012. Review on NSAIDs: Frequently Used Drugs with Underlying Risks. Bangladesh Pharm. J. 15, 187-191.

Korsmeyer, R.W. and Peppas, N.A. 1983. In: Controlled release delivery systems (Roseman, T.J. and Mansford, S.Z. Eds.), Marcel Dekker, New York, pp. 77-90

Lanza, F.L., Chan, F.K., Quigley, E.M. and Practice Parameters Committee of the American College of Gastroenterology. 2009. Guidelines for prevention of NSAID-related ulcer complications. Off. J. Am. Coll. Gastroenterol. ACG. 104, 728-738.
Pharmacopoeia, B. and Volume, I.I. 2007. The Stationery Office on behalf of the Medicines and Healthcare products Regulatory Agency (MHRA). London, UK, Edn. 5.

Pharmacopoeia, U.S. 2004. 30(6) Harmonization: 1174Powder flow. This article was retrieved from https://www.usp.org/sites/default/files/usp/document/h armonization/gen-chapter/g05_pf_30_6_2004.pdf.

Pharmacopoeia, U.S. 2006 (a). Monograph DevelopmentCough Cold and Analgesics. United States Pharmacopeial Convention, Volume 31, pp.1102..

Pharmacopoeia, U.S. 2006 (b). Monograph DevelopmentGastrointestinal Renal and Endocrine. United States Pharmacopeial Convention, Volume 30, pp. 883.

Pharmacopoeia, U.S. 2006 (c). Monograph DevelopmentCough Cold and Analgesics. United States Pharmacopeial Convention, Volume 27, pp.1100. This article was retrieved from http://www.pharmacopeia. cn/v29240/usp29nf24s0_m39860.html.

Pharmacopoeia, U.S. 2006 (d). Monograph DevelopmentGastrointestinal Renal and Endocrine. . United States Pharmacopeial Convention, pp. 881. This article was retrieved from http://www.pharmacopeia.cn/v29240/ usp29nf24s0_m32600.html.

Roth, S.H. 2012. Coming to terms with nonsteroidal antiinflammatory drug gastropathy. Drugs. 72, 873-879.

Rudnic, E. and Schwartz, J.B. 1990. Oral solid dosage forms In: Remington's Pharmaceutical Sciences. Ed. Gennaro. AR Mack Publishing Company, Pennsylvania, USA, pp.1633-1665.

Slowiczek, L. 2018. Ibuprofen vs. Naproxen: Which one should I use? Healthline. This article was retrieved from https://www.healthline.com/health/painrelief/ibuprofen-vs-naproxen.

Vakil, N. 2020. Drug treatment of gastric acidity. MSD man. This article was retrieved from https://www. msdmanuals.com/professional/gastrointestinal-disorders/gastritis-and-peptic-ulcer-disease/drug-treatmentof-gastric-acidity.

World Health Organization. 2012. Bulk density and tapped density of powders. Geneva: WHO. This article was retrieved from http://www.who.int/Bulk-tappeddensityQAS11_450FINAL_MODIFIEDMarch2012.p df 